\title{
Worm genes harnessed to tackle snail fever
}

David Cyranoski, Shanghai

Geneticists are taking some early steps towards a fresh strategy to combat'snail fever', a potentially fatal liver disease that affects more than a million people in China.

A team led by scientists at the Chinese National Human Genome Center in Shanghai this week published details of some 13,000 genes of the parasitic worm Schistosoma japonicum that causes the condition (W. Hu et al. Nature Genet. doi:10.1038/ng1236). Researchers now hope that an analysis of the parasite's genome will help to combat its spread.

The worm lives in freshwater snails found chiefly along the Yangtze river in central China. According to Chinese researchers, snail fever, or schistosomiasis, was fairly prevalent until the 1950s, when rudimentary public-health measures helped to curb its spread. But it has recently been making a comeback, and in July Chinese vice-premier Yi Wu ranked it next to severe acute respiratory syndrome (SARS) and AIDS as one of China's main public-health challenges.

Other species of the worm, most notably S. mansoni, infect humans, mainly in South America and Africa. The World Health Organization estimates that up to 200 million people in more than 70 countries are infected with Schistosoma.

The worm passes from its host into fresh water, from where it can penetrate human skin and infect various organs. About 40 days after entering the body, it produces eggs in the liver that can block blood flow there.

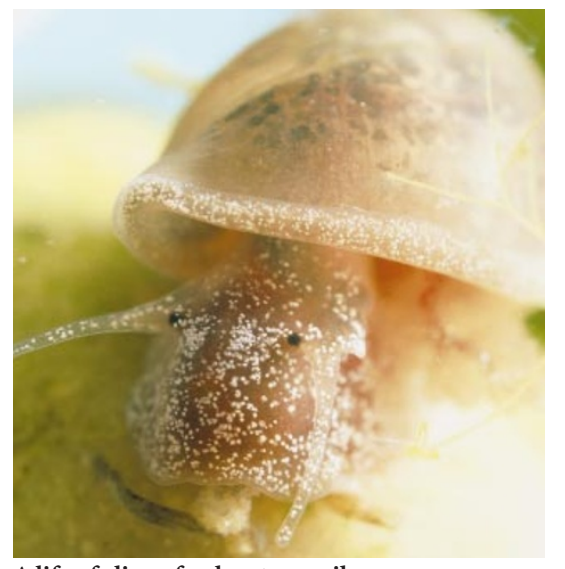

A life of slime: freshwater snails can carry a parasite that causes liver disease in people.

Symptoms include fever, stiffness of limbs and an enlarged liver and spleen. Up to 65 million people living in tropical areas of China are at risk of contracting the potentially fatal disease, public-health officials say.

Almost 50 years ago, China's government mobilized tens of thousands of peasants to take steps to reduce the number of people infected, including collecting and burying snails in soil. But recently the number of cases has increased again. The World Health Organization has cited construction of the Three Gorges Dam on the Yangtze as a possible factor in the disease's revival.

Schistosomiasis can be treated with various drugs, but these are expensive and do not prevent reinfection. Health officials are also concerned that the worm may become resistant to drug treatment.

Ze-Guang Han, the geneticist who led the latest study, says that his team has identified several candidate genes encoding proteins that are specific to the worm and that could be used as the basis for a vaccine to immunize people against the disease. They include proteins found on the parasite's cell membrane and those involved in egg generation. "The development of a vaccine is critical for many developing countries," Han says.

According to the researchers, their work also offers some insight into the worm's unusual life cycle. Early on, for example, the male and female parasites are separate entities, but as adults the female lives tucked inside the male. "Biologically, this is a unique organism for study," says Guo-Ping Zhao, the Shanghai centre's deputy director.

The study shows that many receptor proteins on the surface of worm cells, which respond to signalling molecules from other cells, are similar to those found in the worm's various hosts. This partly explains how the worm hijacks its host's signals to spur its own proliferation and how it evades detection by the host's immune system. "We can really understand the interplay between the host and parasite," says Han.

The Shanghai centre now plans to sequence the parasite's entire genome, which is estimated to contain up to 270 million base pairs. Researchers in the United States are already leading an international effort to sequence the genome of S. mansoni.

\section{Chemists seek image overhaul}

\section{Helen Pearson, New York}

The annual meeting of the American Chemical Society (ACS), held in New York last week, saw chemists address perhaps the biggest problem facing their discipline: why young people are turning their backs on it.

The number of US bachelor's degrees awarded in chemistry fell by $8 \%$ between 1997 and 2001, society officials said. If the trend continues, "we could put ourselves out of business", warned environmental chemist Alan Elzerman of Clemson University in South Carolina.

Speakers told a seminar on 9 September that the discipline's best prospects lie in reinventing the undergraduate chemistry curriculum. The same lacklustre lectures and textbooks have been lulling students to sleep for decades, they said.

The seminar followed on from a threeday meeting in Washington DC in June, which brought together around 50 chemists and science educators. And its conclusions echoed those of the June meeting, with participants agreeing that one reason that courses don't attract students is chemistry's generally poor public image. Chemistry departments also fail to advertise overlapping, 'sexy' disciplines such as nanotechnology or proteomics, they added.

The National Science Foundation (NSF) has ploughed \$15 million-20 million over the past ten years into initiatives aimed at revamping the chemistry undergraduate curriculum, but the effort needs even more investment, said Eli Pearce of the Polytechnic University in New York, a former ACS president.

But some scientists claim that the ACS's own membership is too old to relate to young people's doubts about chemistry. Nearly $40 \%$ of its 163,000 members are over 51 - compared with $11 \%$ aged 30 or below. Some seminars "look like something out of a

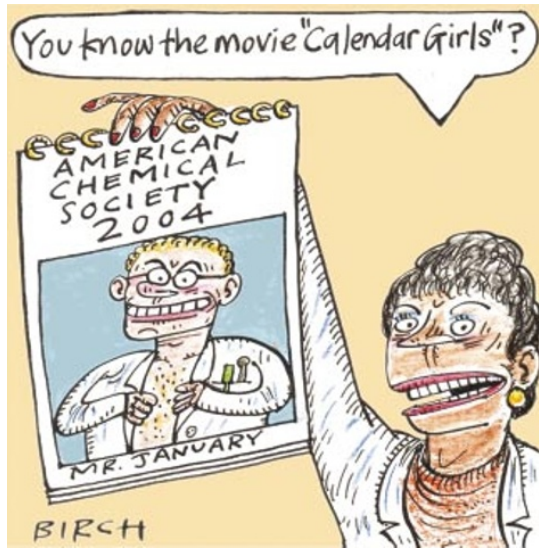

retirement community", says 31-year-old Darrell Coleman of drug firm Eli Lilly at Research Park Triangle, North Carolina.

Sylvia Ware, an ACS official working with its education committee, says that some of its members aren't facing up to the issue. "I think we underestimate the level of effort needed," she says. "There won't be major change until the grass roots say we need it." 